\section{Acute Motor and Sensory Axonal Neuropathy (AMSAN) and Immune Thrombocytopenic Purpura (ITP) Related to Hemophilus Influenzae}

\author{
Vivek Satyasi, $\mathrm{MD}^{1}$; Aiesha Ahmed, $\mathrm{MD}^{1,2}$; \\ Amtul Farheen, MD ${ }^{1,3}$
}

'Penn State Hershey Medical Center, Hershey, PA (Department of Neurology)

${ }^{2}$ Spectrum Health, Grand Rapids, MI (Department of Neuroscience)

${ }^{3}$ Lebanon VA Medical Center, Lebanon, PA

(Department of Neurology)

\section{ABSTRACT}

We describe a rare case presenting with signs of acute motor and sensory axonal neuropathy (AMSAN) and immune thrombocytopenic purpura (ITP) possibly triggered by Hemophilus influenzae. Guillain-Barre syndrome (GBS) is an autoimmune disorder purported to be due to molecular mimicry, often with a preceding infection, leading to myelin sheath or even axonal damage, in the peripheral nervous system. There have been rare occasions of concurrent GBS and ITP, but even rarer is the presence of both AMSAN and ITP, which requires quick recognition and evaluation. This case highlights the need for a thorough initial history taking and a general physical exam, in addition to unique management decisions and strategies in patients with suspected GBS as there may be signs of other associated disorders that require immediate attention.

\section{Keywords: $G B S, A M S A N$, ITP}

\section{Case Report}

A 42-year-old man with a past medical history of nephrolithiasis and mitral valve prolapse had been experiencing sinus congestion and pressure that he had been treating with Nyquil for a week prior to presentation. He stated that his symptoms had been improving until 2 days prior when he began to experience progressive upper and lower extremity, distal greater than proximal, numbness and tingling that eventually progressed to his elbows and his ankles. He was stumbling as he attempted to walk and presented to the emergency department (ED). In the ED, there was concern for posterior circulation stroke, but NIH stroke scale was zero without any extremity ataxia. CT scan of the brain showed no hemorrhage or ischemic stroke. Vital signs were stable and he was afebrile. Neurological examination revealed no mental status, cranial nerve, motor, sensory, or coordination deficits, but he was completely areflexic. General examination showed oropharyngeal wet purpura with glossal and palatal lesions, raising concern for coagulopathy. Complete blood count revealed a low platelet level of 3000/mcL with an otherwise normal white blood cell and hemoglobin level.

Hematology recommended immediate platelet transfusion of four units and starting IVIG for suspected ITP. Given the high index suspicion for Guillain-Barre syndrome, we determined that IVIG would be the best option in treating both conditions. Initially, there was no respiratory distress (initial negative inspiratory force was at $-40 \mathrm{~cm} \mathrm{H} 2 \mathrm{O}$, vital capacity was 2.2L). However, his vital capacity decreased to $1.7 \mathrm{~L}$ and on the third day of hospitalization he was promptly intubated given further declining vital capacity (0.61L). A respiratory viral panel revealed Haemophilus influenzae positivity and he was started on a seven-day course of Azithromycin. Nerve conduction studies are summarized in Table 1. Needle examination revealed increased insertional activity and fibrillations in only the right tibialis anterior muscle. Motor unit potentials showed reduced recruitment with normal duration, amplitude in most of the tested muscles.

Over the course of the next two days, he completed a course of IVIG at $2 \mathrm{~g} / \mathrm{kg}$, and an improvement in platelet count was noted, however he continued to decline neurologically with significant quadriparesis (motor strength $1 / 5$ in each extremity). Sensory examination was notable at this time for diminished light touch sensation in bilateral lower extremities. Given his continuing decline, he was started on plasmapheresis for 5 sessions with partial improvement in strength with exam notable for $4 / 5$ strength in most upper extremity muscle groups and $3 / 5$ for most lower extremity muscle groups. Tracheostomy was performed initially; however, gradually he was weaned off the ventilator. Given his significant dysphagia, a PEG was placed.

After 3 weeks, he was discharged to a local rehabilitation facility and he continued to improve in his strength, dysphagia, respiratory function. The tracheostomy tube was decannulated and PEG tube removed. He was able to eat a regular diet in 2 weeks and ambulate without assistance for several minutes at a time, needing periods of rest due to fatigue.

At 12-month follow up, patient was able to work full time, had mild fatigue and some paresthesias, however neurological examination revealed normal strength and sensation. He had no further recurrence of presenting symptoms and recovered reasonably well. 
Table 1. Nerve conduction studies in a patient with AMSAN at 3 weeks from symptom onset

\begin{tabular}{|c|c|c|c|c|c|c|}
\hline Nerve & $\begin{array}{l}\text { Sensory Peak } \\
\text { Latency (ms) }\end{array}$ & $\begin{array}{l}\text { Sensory Distal } \\
\text { Amplitude } \\
(\text { MicroV) }\end{array}$ & $\begin{array}{l}\text { Motor Distal } \\
\text { Latency (ms) }\end{array}$ & $\begin{array}{l}\text { Motor Distal } \\
\text { Amplitude } \\
(\mathrm{mV})\end{array}$ & $\begin{array}{l}\text { Motor } \\
\text { Conduction } \\
\text { Velocity }(\mathrm{m} / \mathrm{s})\end{array}$ & $\begin{array}{l}\text { F Wave } \\
\text { Latency (ms) }\end{array}$ \\
\hline Median* & $3.39(<3.7)$ & $6.6(>20)$ & $3.54(<4.4)$ & $7.1(>4.0)$ & $51.3(>49.0)$ & $\mathrm{NR}(<3 \mathrm{l})$ \\
\hline Ulnar* $^{*}$ & $3.28(<3.5)$ & $7.0(>10.0)$ & $2.24(<3.8)$ & $6.5(>6.0)$ & $52(>49.0)$ & $\mathrm{NR}(<32)$ \\
\hline Radial $^{* *}$ & $2.4(<2.9)$ & $6.7(>15)$ & & & & \\
\hline Tibial $^{\wedge}$ & & & $5.21(<6.1)$ & $1.8(>3)$ & $48.3(>41)$ & NR \\
\hline Peroneal $^{\prime}$ & & & $6.41(<6.1)$ & $0.9(>5.0)$ & $42.5(>44)$ & \\
\hline Sural & $2.97(<4.2)$ & $4.2(>6.0)$ & & & & \\
\hline $\begin{array}{l}\text { Superficial } \\
\text { Peroneal }\end{array}$ & $\mathrm{NR}$ & NR & & & & \\
\hline
\end{tabular}

$\mathrm{NR}=$ no response. Normal values in parentheses.

*Stimulating wrist, recording digits 2 or 5 (sensory) or recording abductor pollicis brevis or abductor digiti minimi muscle (motor).

**Stimulating forearm, recording anatomical snuff box.

^Stimulating ankle, recording extensor digitorum brevis muscle.

^Stimulating ankle, recording abductor hallucis muscle.

\section{Discussion}

Gullian-Barre syndrome (GBS) is a disease in which there is typically damage to myelin surrounding peripheral nerves and typically presents as the classic ascending weakness, paresthesias, and numbness, all potentially in the setting of a preceding infection; this pattern is particularly associated with the GBS-subtype of Acute Inflammatory Demyelinating Polyradiculoneuropathy (AIDP) ${ }^{1,2}$. There are several other variants of GBS, one of which is Acute Motor and Sensory Axonal Neuropathy (AMSAN), which carries a worse prognosis and causes axonal injury rather than pure demyelination ${ }^{1,3}$. Compared to AIDP, AMSAN patients tend to progress much more quickly, have a higher chance of becoming debilitated and quadriparetic and have a longer time for recovery. AIDP tends to be a predominantly T-cell mediated disorder, whereas AMSAN is typically more B-cell mediated; however, it still responds to the same recommended initial treatments for GBS, such as intravenous immunoglobulin (IVIg) and plasmapheresis ${ }^{3}$.

ITP is characterized by depletion of platelets due to an auto-antibody mediated process targeting surface glycoproteins, specifically GpIIb-IIIa. There is thus far, no known common receptor or process that has linked both GBS and ITP. However, as molecular mimicry is the underlying mechanism for both these diseases, there is a chance for both these entities to co-occur in the same patient as was the case with our patient and a few other patients in the literature ${ }^{1,4}$.
In our patient, IVIG was used to treat both ITP and suspected GBS. While his ITP resolved fairly quickly with the treatment within a span of a week, his presentation of AMSAN continued to progress to respiratory distress and quadriparesis which only began to improve 3 weeks after initial presentation after 5 sessions of plasmapheresis.

In our patient, Haemophilus influenzae was detected. There have been cases of both GBS and ITP associated with this bacteria, as well as a case reported with both GBS and ITP $^{5}$. Mori et al. investigated the link between $H$. influenzae and GBS and suspected that recovery was actually improved if GBS was associated with antecedent respiratory infection with this bacterium, and that EMG in these cases actually showed increased rate of axonal variants ${ }^{6}$, such as was observed in our case.

Our patient did not have significant cranial nerve involvement and did in fact have recovery to the point of functioning independently close to 12 months after initial presentation. Additionally, out of all the previous cases, the patient reported by Ward et al. is the only other patient who was treated with plasmapheresis ' ${ }^{1}$ This illustrates the heterogeneity of presentation and treatment even in patients with AMSAN. There have been at least a few cases of various different subtypes of GBS and ITP suggesting that while it is a rare occurrence, there does seem to be some underlying process that increases the risk of an additional autoimmune reaction in a patient already suffering from one $1,7,8,9,10,11,12,13,14,15$. Finally, this case does highlight the unique management and diagnostic decision-making in a patient with both ITP and AMSAN. 


\section{Corresponding Author}

Amtul Farheen, MD

Lebanon VA Medical Center

Department of Neurology

1700 South Lincoln Ave,

Lebanon, PA, 17042

Phone: 001-717-272-6621 Ext: 6117

Fax: 001-717-228-5982

Email: farheenbright@gmail.com

\section{References}

1. Ward IM, Fewell AE, Ferraro DM, Morris MJ. Concurrent acute motor and sensory axonal neuropathy and immune thrombocytopenic purpura. Mil Med. 2013 Mar;178(3):e367-71. doi: 10.7205/MILMED-D-12-00306. PMID: 23707127.

2. Dimachkie MM, Barohn RJ. Guillain-Barré syndrome and variants. Neurol Clin. 2013 May;31(2):491510. doi: 10.1016/j.ncl.2013.01.005. Epub 2013 Feb 19. PMID: 23642721; PMCID: PMC3939842.

3. Sheikh KA. Guillain-Barré Syndrome. Continuum (Minneap Minn). 2020 Oct;26(5):1184-1204. doi: 10.1212/ CON.0000000000000929. PMID: 33002998.

4. Sato N, Kamata T, Akiyama N, Kuwana M, Kanda T. Acute inflammatory sensorimotor polyradiculoneuropathy associated with immune thrombocytopenic purpura. J Intern Med. 2005 May;257(5):473-7. doi: 10.1111/j.13652796.2005.01479.x. PMID: 15836665.

5. Condon EM, Tobin A. Haemophilus influenzae associated Guillain BarréSyndrome with thrombocytopenic purpura and hyperthermia. Anaesth Intensive Care. 2008 Sep;36(5):722-5. doi: 10.1177/0310057X0803600516. PMID: 18853594.

6. Mori M, Kuwabara S, Miyake M, Noda M, Kuroki H, Kanno H, Ogawara K, Hattori T. Haemophilus influenzae infection and Guillain-Barré syndrome. Brain. 2000 Oct;123 ( Pt 10):2171-8. doi: 10.1093/brain/123.10.2171. PMID: 11004133.

7. Zeidman LA, Fahey CD, Grinblatt DL, Harsanyi K. Immunoglobulin for concurrent Guillain-Barré and immune thrombocytopenic purpura. Pediatr Neurol. 2006 Jan;34(1):60-2. doi: 10.1016/j.pediatrneurol.2005.06.012. PMID: 16376282

8. Gross PT. Acute idiopathic polyneuritis and idiopathic thrombocytopenic purpura. JAMA. 1980 Jan 18;243(3):256-7. PMID: 7188622.
9. Fukayama M, Murai Y, Ikebuchi K, Miwa A, Kurata H, Mori M. [Acute polyradiculoneuritis with thrombocytopenia following rubella infection]. Rinsho Ketsueki. 1983 Nov;24(11):1534-8. Japanese. PMID: 6672275

10. Khaldi F, Larnaout A, Miladi N, Bennaceur B. Guillain-Barré syndrome and idiopathic thrombocytopenic purpura. Can J Neurol Sci. 1990 Feb;17(1):95. doi: 10.1017/ s0317167100030134. PMID: 2311022

11. Combarros O, Calleja J, Hernández L, Polo JM, Berciano J. Guillain-Barré syndrome associated with idiopathic thrombocytopenic purpura. J Neurol Neurosurg Psychiatry. 1991 Jul;54(7):654-5. doi: 10.1136/ jnnp.54.7.654-a. PMID: 1895135; PMCID: PMC1014444.

12. Vashista A, Goel A, Bhatnagar MK, Malhotra M, Verma NP. Idiopathic thrombocytopenic purpura and acute polyneuritis: a coincidence or association? Postgrad Med J. 1992 May;68(799):394-5. doi: 10.1136/pgmj.68.799.394-a. PMID: $1631000 ;$ PMCID: PMC2399398.

13. Corbanese U, Martinuzzi A, Possamai C, Romeo G, Possamai G, Trubian L. Guillain-Barré syndrome with associated thrombocytopenia: prompt response to combined corticosteroid and immunoglobulin treatment. Neuromuscul Disord. 1998 Feb;8(1):50-2. doi: 10.1016/ s0960-8966(97)00146-6. PMID: 9565991.

14. Gaur S, Reddy S, Baumann MA. Acute inflammatory demyelinating polyneuropathy concurrent with Evans syndrome. South Med J. 2003 Jan;96(1):1067. doi: 10.1097/01.SMJ.0000049849.49028.6B. PMID: 12602738 .

15. Kohli RS, Bleibel W, Bleibel H. Concurrent immune thrombocytopenic purpura and Guillain-Barre syndrome in a patient with Hashimoto's thyroiditis. Am J Hematol. 2007 Apr;82(4):307-8. doi: 10.1002/ajh.20771. PMID: 16986132.

16. Furukawa Y, Iwasa K, Ono K, Yamada M. Fisher syndrome associated with immune thrombocytopenic purpura. Intern Med. 2011;50(6):631-3. doi: 10.2169/ internalmedicine.50.4621. Epub 2011 Mar 15. PMID: 21422692. 